\section{Trajectories of cognitive decline over 10 years in a Brazilian elderly population: the Bambuí Cohort Study of Aging}

\author{
Trajetória no longo prazo do declínio cognitivo \\ entre idosos brasileiros: Estudo de Coorte de \\ Idosos de Bambuí
}

\footnotetext{
1 Núcleo de Estudos em Saúde Pública e Envelhecimento, Fundação Oswaldo Cruz/Universidade Federal de Minas Gerais, Belo Horizonte, Brasil. 2 Institute of Psychiatry, King's College, London, UK.

Correspondence E. Castro-Costa Núcleo de Estudos em Saúde Pública e Envelhecimento, Fundação Oswaldo Cruzl Universidade Federal de Minas Gerais.

Av. Augusto de Lima 1715 6 o andar, Belo Horizonte, $M G$ 30130-002, Brasil. castro-costa@cpqrr.fiocruz.br
}

\section{Abstract}

Few population-based studies have examined long term cognitive trajectory, and these studies were conducted in high income countries. We investigated the association of age, gender and education with 10-year cognitive trajectory in a welldefined population of elderly using data from the Bambui Cohort Study of Aging, in Brazil. Cognition was measured using the Mini- Mental State Examination (MMSE). Cohort members underwent annual follow-ups. This analysis was based on 12,206 MMSE measurements from 1,461 (91\%) baseline participants. We used mixed effects models to study MMSE as outcome. The key findings from this analysis are that women and people with a higher schooling level at baseline had high scores of MMSE, while older participants started off lower. Regarding cognitive decline, women, older people and those with a higher schooling level declined faster.

Cognition; Mental Health; Aged; Cohort Studies

\author{
Erico Castro-Costa 1,2 \\ Michael E. Dewey 2 \\ Elizabeth Uchôa 1 \\ Josélia O. A. Firmo 1 \\ Maria Fernanda Lima-Costa 1 \\ Robert Stewart 2
}

\section{Introduction}

There is a normal process of age related cognitive decline across the life span characterized by increasing difficulties with memory, speed of information processing, language and other cognitive functions. More intense closing stages of decline in cognition tend to be defined as dementia but decline in the non-demented population has also been shown repeatedly with some cognitive functions more affected than others. Although cognitive decline is known to increase with age 1,2 , low-education levels $1,3,4$ and inconsistently associated with gender $2,3,4,5,6$, in crosssectional studies, measurement of trajectories and production of these trajectories are much less certain.

Few studies have investigated the relationship of basic variables such as age, gender and education in cognitive trajectories in demented and non-demented. In demented participants, Wilkosz et al. 7 showed six trajectories with significantly different courses and rates of cognitive decline. These trajectories were best defined by subject age and Mini-Mental State Examination (MMSE) 8 score at the initial assessment. In general, subjects with older age followed a trajectory with slower cognitive decline. Participants with higher initial MMSE scores tended to follow trajectories of slower decline, while those with lower initial scores tended to decline more rapidly. 
Among studies that have focused on nondemented participants, one in the United States demonstrated that cognitive decline was faster in older cohorts, women, widowed, and never-married individuals but was slower in non-Hispanic black Americans 9. However, at first assessment, women had higher scores than men, and nonHispanic black Americans had lower scores than non-Hispanic white Americans. Educational level was not associated with rate of decline in cognition scores. Another study carried out in the United Kingdom, demonstrated that education and social class were not related to decline and increased rate of change ${ }^{10}$. In contrast, poor mobility was associated with lower cognitive performance, increased cognitive decline and increased rate of change of cognitive decline.

Although, some studies have examined the trajectory of cognitive decline, as mentioned above, to our knowledge there has been no research carried out in a developing country. Developing countries have on average lower education levels but also a much wider range of educational levels and hence it might be possible to demonstrate a relationship between education and cognitive decline, which is attenuated in developed countries by the restricted range.

In this study, we investigated the association of age, gender and education with trajectories of cognitive decline in a well-defined population of Brazilian elderly with low-education levels, using data from a 10-year population-based cohort study.

\section{Methods}

\section{Study area and population}

This analysis was carried out using data from the Bambuí Cohort Study of Aging, which took place in Bambuí, a town of approximately 15,000 inhabitants, situated in Minas Gerais State in Southeastern Brazil. In the study area, the human development index (a composite statistic used as an index to rank countries by level of "human development") was 0.70 , which implies medium development, and the life expectancy was 70.2 years in 1991 11. The city had one general hospital and approximately one physician per 1,000 inhabitants. The main economic activities were agriculture (particularly farming) and commerce 11.

The Bambuí Cohort Study of Aging procedures have been described in detail elsewhere 11,12. Briefly, the baseline cohort population comprised all residents aged 60 and over on January 1st, 1997 who were identified by means of a private census in the city. From a total of 1,742 older residents identified in this census, 1,606 (92.2\%) participated in the baseline survey. Baseline data collection was carried out from February to May 1997, comprising standardized interviews and selected biological measures. Cohort members underwent annual follow-up, consisting of standardized interviews, and verification of death certificates.

\section{Study variables}

\section{- Cognition assessment}

The Bambuí cohort interview includes a standard Brazilian version of the MMSE 13. In the Brazilian validation study, some questions were modified according to their relevance to the target population 14. In the orientation section by Fostein et al. 8 questions about the season of the year, building, and floor were replaced by period of the day, room, and address 13 . In the registration and recall section, the words used were cat, tree, and guitar (those words in Portuguese are gato, árvore and violão). In the attention and calculation section, serial fives replaced serial sevens, and "Maria", which is more commonly used in Brazilian culture, replaced spelling "world" backwards. The MMSE is a widely used instrument for assessing cognitive impairment ${ }^{8}$. However, its application in research is much broader, in particular as a measure of cognitive function in clinical and epidemiological studies of persons without dementia.

\section{- Exploratory variables}

Age, gender and schooling were considered as exploratory variables in the present analysis.

\section{Statistical analysis}

We used mixed effects models to study MMSE as outcome with sex, age group (four levels: 60-64, $65-69,70-74,75$ or more years old) and education (three levels: 3 or less, 4-7, 8 or more years of schooling) and as exposures. Also, since it is important to take account of the dropout in longitudinal studies like this, a further factor, pattern, was included to indicate at which point in time the last valid observation occurred. Time was included in the model in years and as an interaction with pattern. Three separate models were fitted to incorporate each of the three interactions of interest: time with each of sex, education and age group. The models include a random intercept and random slope for time within participant to account for the correlation between observations. The analysis was performed using the R software 
(The R Foundation for Statistical Computing, Vienna, Austria; http://www.r-project.org).

\section{Results}

The total number of participants who answered the MMSE in the baseline of the Bambuí Cohort Study of Aging was 1,558 (97\%). However, participants with only one observation were excluded from the main analysis, as they did not allow for estimation of time trends. Participants with missing education (two participants) were also excluded. This left 1,461 participants. The median age at entry was 69.1 years (standard deviation $-\mathrm{SD}=7.3$ ) and $60.2 \%$ were female. The mean number of cognition assessment visits was 7.9, consisting of a total of 12,206 MMSE measurements.

Overall mean score of MMSE at baseline was 24.2 ( $\mathrm{SD}=4.8$ ) with higher values among women in comparison with men $[$ mean $=24.9$ (SD = 4.6) and $23.3(\mathrm{SD}=5.1)$ ]. In general, the mean baseline MMSE score decreased with age, and increased with schooling level, and were higher among women in all groups (Table 1).

Table 2 shows the results of three separate mixed models to test primarily interactions between gender, education, age and MMSE score trajectory. Each model is adjusted for the other two main effects. In model 1 , the positive coefficient for the main effect of gender indicates a higher initial level of 0.4 MMSE points in women. However, the significant negative interaction with slope indicates a faster decline in MMSE in women so that the performance of the two sexes is equivalent after about four years with women predicted to score lower from then on.

The model 2 investigated the effect of education on slope. Main effects indicated higher initial MMSE scores for those with higher education levels, and the significant interaction along with the interaction term coefficients indicate a faster decline associated with higher education although these interaction term coefficients did not change in a monotonic fashion across the three education groups and slopes were similar for groups with 4-7 and $>8$ years education.

Finally, the model 3 investigated the effect of age group on slope. Main effects for age do not indicate a monotonic association with initial MMSE score. However, the significant interaction indicates faster decline with increasing age, especially for the two oldest groups. The results for the dropout patterns and their interaction with time are not presented but in general show that participants who dropped out early had a steeper rate of decline than later dropouts.

\section{Discussion}

In this prospective population-based cohort study, carried out in a well-characterized large Brazilian elderly population, we modelled the effects of age, gender and education on initial cognitive performance measured by the MMSE and rate of decline. The key findings from this analysis are that women and people with higher levels of education at baseline have high scores of MMSE,

Baseline Mini-Mental State Examination score (MMSE), by gender. The Bambuí Cohort Study of Aging, 1997.

\begin{tabular}{|c|c|c|c|c|}
\hline Variables & $\begin{array}{c}\text { Total }(\mathrm{N}=1,461) \\
\text { Mean (SD) }\end{array}$ & $\begin{array}{c}\text { Men }(n=584) \\
\text { Mean (SD) }\end{array}$ & $\begin{array}{c}\text { Women }(\mathrm{n}=877) \\
\text { Mean (SD) }\end{array}$ & p-value * \\
\hline Overall & $24.26(4.88)$ & 23.27 (5.09) & $24.92(4.62)$ & $<0.0001$ \\
\hline \multicolumn{5}{|c|}{ Age group (years) } \\
\hline $60-64$ & $25.35(4.30)$ & $24.26(4.45)$ & $26.12(4.02)$ & $<0.0001$ \\
\hline $65-69$ & $24.35(4.32)$ & $23.50(4.66)$ & $24.89(4.02)$ & \\
\hline $70-74$ & $24.36(4.69)$ & $23.35(5.24)$ & $25.02(4.18)$ & \\
\hline 75 or more & $22.48(5.85)$ & $21.39(5.84)$ & $23.18(5.76)$ & \\
\hline \multicolumn{5}{|c|}{ Education (years) } \\
\hline$<3$ & $22.87(5.06)$ & $21.58(5.27)$ & $23.66(4.75)$ & $<0.0001$ \\
\hline $4-7$ & $26.57(3.21)$ & $25.82(2.94)$ & $27.12(3.30)$ & \\
\hline 8 or more & $27.92(2.18)$ & $27.27(2.23)$ & $28.42(2.02)$ & \\
\hline
\end{tabular}

SD: standard deviation.

* Students' t test for overall and Anova for age group and education. 
Mutually adjusted gender, age and education associations with trajectories of Mini-Mental State Examination score (MMSE). The Bambuí Cohort Study of Aging, 1997-2007.

\begin{tabular}{|c|c|c|c|}
\hline \multirow[t]{2}{*}{ Variables } & Model 1 & Model 2 & Model 3 \\
\hline & $\beta(95 \% \mathrm{Cl})$ & $\beta(95 \% \mathrm{Cl})$ & $\beta(95 \% \mathrm{Cl})$ \\
\hline Intercept & 25.18 ( 24.76 to 25.60$)$ & 25.48 (25.08 to 25.89$)$ & \\
\hline \multicolumn{4}{|l|}{ Gender } \\
\hline Female vs. male & $0.40(0.03$ to 0.78$)$ & & \\
\hline \multicolumn{4}{|l|}{ Education (years) } \\
\hline $4-7$ vs. $\leq 3$ & & 3.05 (2.63 to 3.47 ) & \\
\hline$\geq 8$ vs. $\leq 3$ & & 4.23 (3.56 to 4.89$)$ & \\
\hline \multicolumn{4}{|l|}{ Age (years) } \\
\hline $65-69$ vs. $60-64$ & & & $-0.67(-1.13$ to -0.20$)$ \\
\hline $70-74$ vs. $60-64$ & & & $-0.39(-0.91$ to 0.14$)$ \\
\hline$\geq 75$ vs. $60-64$ & & & $-1.08(-1.62$ to -0.54$)$ \\
\hline \multicolumn{4}{|l|}{ Gender by time } \\
\hline Males by time & $0.01(-0.02$ to 0.05$)$ & & \\
\hline Females by time & $-0.10(-0.13$ to -0.08$)$ & & \\
\hline \multicolumn{4}{|l|}{ Education by time } \\
\hline$\leq 3$ years by time & & $-0.04(-0.07$ to -0.02$)$ & \\
\hline 4-7 years by time & & $-0.10(-0.14$ to -0.07$)$ & \\
\hline$\geq 8$ years by time & & $-0.09(-0.16$ to -0.03$)$ & \\
\hline \multicolumn{4}{|l|}{ Age by time } \\
\hline 60-64 years by time & & & $-0.03(-0.06$ to 0.00$)$ \\
\hline 65-69 years by time & & & $-0.04(-0.08$ to 0.00$)$ \\
\hline $70-74$ years by time & & & $-0.10(-0.15$ to -0.06$)$ \\
\hline 75 or more years by time & & & $-0.21(-0.26$ to -0.15$)$ \\
\hline Likelihood-ratio test & $\chi^{2}: 35.9 ;$ df: 2 & $\chi^{2}: 8.6 ; d f: 2$ & $\chi^{2}: 38.3 ;$ df: 3 \\
\hline $\mathrm{p}$-value & $<0.0001$ & 0.0136 & $<0.0001$ \\
\hline
\end{tabular}

Model 1: adjusted by education and age; Model 2: adjusted by gender and age; Model 3: adjusted by gender and education.

while older participants started off lower. Regarding cognitive decline, women, those with higher education and older people declined faster.

The current study is, to our knowledge, the first investigation of cognitive trajectories to have been carried out in a low or middle-income country in a population with a low education level, adding to the relatively few longitudinal studies that have investigated this. Its strengths include the large population-based cohort followed over an extended period and the annual examination of cognitive performance over a long period of time using a widely applied brief assessment measure (the MMSE) administered in an identical format. It also provides supportive evidence that the MMSE, although relatively crude, is adequate to pick up variations between individuals and influences on decline over the period studied. The main limitations are the assumptions in the models of a linear decline and further assumptions regarding dropout patterns being the same whether dropout is due to refusal or death.

Studies investigating the trajectory of cognitive decline in older populations are rare $8,9,10$ and fail to find a consistent education effect. Anstey \& Christensen 15 , in a review of the literature, identified 14 studies that examined the effect of education as a risk factor for cognitive decline in old age, but results were not consistent. All studies using mental status measures 16,17,18,19,20,21,22 such as MMSE (used and Bambuí) found a protective effect of education, while studies including measures of memory, verbal fluency/vocabulary and those that involve reasoning and induction showed $75 \%, 71 \%$ and none protective effects of education, respectively. However more recently, two studies 9,10 assessing cognitive function using mental status measures, MMSE and the Telephone Interview for Cognitive Status (a validated 
assessment tool comparable to the MMSE 22) did not find a protective effect of education.

Findings from our study are mostly comparable with those from previous reports in which the same exposure measure (mental status measure) was administered to older adults in longitudinal population-base surveys 9,10,16,17,18,19,20,21,22 The previous findings at baseline of most studies demonstrated that women had higher scores than men and older participants had lower scores than younger participants and are consistent with our findings 9,10,16,17,18,19,20,21,22 .

Finally, our education findings (highly educated groups decline faster) are not consistent with previous studies; those in which education has a protective effect $16,17,18,19,20,21,22$ and those studies where education was not related to cognitive decline 9,10 . The explanation for this difference may be based on differences on the level of education across studies or a floor effect in poorly educated persons 23 . While in all previous studies most participants have more than eight years of schooling, in Bambuí only $7.9 \%$ of participants have eight or more years of education, leading to differences in categorizing the variable. Possibly, we can explain the association of the highly edu- cated group of current study (eight or more years of schooling) and cognitive decline, because the highly educated group of current study belongs to the low educated group categorization of those previous studies 9,10,16,17,18,19,20,21,22. Studies, such as Lyketsos et al. 18 (0-8, 9-11, 12,13-15 and 16 or more years of schooling), Farmer et al. 20 (0-9, 10-12 and more than 12 years of schooling), Karlamangla et al. $9(0-7,8-11,12-14$, more than 14 years of schooling) and Muniz-Terrera et al. 10 (0-14, 15 or more years of schooling), have focused on subdividing the highly educated group rather than the low educated group, because of a high proportion of educated participants. Regarding the floor effect, the MMSE has been found to have it in different studies and populations and it may have also happened in the current study because of the low education of this population.

In conclusion, in this large cohort of a Brazilian elderly population with low education levels, gender, age and education were associated with long-term rates of cognitive decline. Further analyses are needed to examine the effects of health conditions and other potential confounding variables on the MMSE trajectories.

\section{Resumo}

Poucos estudos de base populacional examinaram a trajetória no longo prazo do declínio cognitivo. Os estudos existentes foram conduzidos em países de alta renda. Nós investigamos as associações entre idade, sexo e escolaridade e o declínio cognitivo em uma população idosa bem definida, utilizando dados de 10 anos de seguimento da coorte de Bambuí, Minas Gerais, Brasil. A cognição foi aferida anualmente por meio do Mini-Exame do Estado Mental (MEEM). Essa análise foi baseada em 12.206 medidas do MEEM de 1.461 (90\%) participantes da linha de base. Foram utilizados modelos de efeitos mistos, considerando-se o escore do MEEM como variável de desfecho. As mulheres e os indivíduos com maior escolaridade apresentaram resultados mais altos no MEEM na linha de base, enquanto que os idosos mais velhos apresentaram pontuações mais baixas. Com relação ao declínio cognitivo, participantes do sexo feminino, com maior escolaridade e mais velhos, apresentam reduções mais rápidas dos escores do MEEM.

Cognição; Saúde Mental; Idoso; Estudos de Coortes

\section{Contributors}

E. Castro-Costa, M. E. Dewey, M. F. Lima-Costa and R. Stewart contributed towards the conception and design, data analysis, interpretation of data and writing of the manuscript. E. Uchôa and J. O. A. Firmo contributed to the data collection, interpretation of data and critical revision of the manuscript.

\section{Acknowledgments}

To CNPq, FINEP and CAPES for their financial support. 
References

1. Crum RM, Anthony JC, Bassett SS, Folstein MF. Population-based norms for the Mini-Mental State Examination by age and education level. JAMA 1993; 269:2386-91.

2. Herrera Jr. E, Caramelli P, Silveira AS, Nitrini R. Epidemiologic survey of dementia in a communitydwelling Brazilian population. Alzheimer Dis Assoc Disord 2002, 16:103-8.

3. Anderson TM, Brodaty H, Trollor JN, Andrews G. Effects of sociodemographic and health variables on Mini-Mental State Exam scores in older Australians. Am J Geriatr Psychiatry 2007; 15:467-76.

4. Huppert FA, Cabelli ST, Matthews FE; MRC Cognitive Function and Ageing Study. Brief cognitive assessment in a UK population sample - distributional properties and the relationship between the MMSE and an extended mental state examinations. BMC Geriatr 2005; 5:7.

5. Espino DV, Lichtenstein MJ, Palmer RF, Hazuda HP. Ethnic differences in mini-mental state examination (MMSE) scores: where you live makes a difference. J Am Geriatr Soc 2001; 49:538-48.

6. Valle EA, Castro-Costa E, Firmo JOA, Uchôa E, Lima-Costa MF. Estudo de base populacional dos fatores associados ao desempenho no Mini Exame do Estado Mental entre idosos: Projeto Bambuí. Cad Saúde Pública 2009; 25:918-26.

7. Wilkosz PA, Seltman HJ, Devlin B, Weamer EA, Lopez OL, DeKosky ST, et al. Trajectories of cognitive decline in Alzheimer's disease. Int Psychogeriatr 2010; 22:281-90.

8. Folstein MF, Folstein SE, McHugh PR. "Mini-mental state". A practical method for grading the cognitive state of patients for the clinician. J Psychiatr Res 1975; 12:189-98.

9. Karlamangla AS, Miller-Martinez D, Aneshensel CS, Seeman TE, Wight RG, Chodosh J. Trajectories of cognitive function in late life in the United States: demographic and socioeconomic predictors. Am J Epidemiol 2009; 170:331-42.

10. Muniz-Terrera G, Matthews F, Dening T, Huppert FA, Brayne C; CC75C Group. Education and trajectories of cognitive decline over 9 years in very old people: methods and risk analysis. Age Ageing 2009; 38:277-82.

11. Lima-Costa MF, Firmo JOA, Uchôa E. Cohort profile: the Bambui (Brazil) Cohort Study of Aging. Int J Epidemiol 2010; [Epub ahead of print].

12. Lima-Costa MF, Firmo JOA, Uchôa E. The Bambuí Cohort Study of Aging: methodology and health profile of participants at baseline. Cad Saúde Pública 2011; 27 Suppl 3:S327-35.
13. Seabra MLV, Concílio GV, Villares JB, Carlini EA. Avaliação do teste "Mini-Mental State" em voluntários e pacientes brasileiros. Rev ABP-APAL 1990; 12:1-7.

14. Castro-Costa E, Fuzikawa C, Ferri CP, Uchôa E, Firmo JOA, Lima-Costa MF, et al. Dimensions underlying the Mini-Mental State Examination in a sample with low-education levels: the Bambui Health and Aging Study. Am J Geriatr Psychiatry 2009; 17:863-72.

15. Anstey K, Christensen H. Education, activity, health, blood pressure and APOE as predictors of cognitive change in old age a review. Gerontology 2000; 46:163-77.

16. Evans DA, Beckett LA, Albert MS, Herbert LE, Scherr PA, Funkenstein HH, et al. Level of education and change in cognitive function in a community population of older persons. Ann Epidemiol 1993; 3:71-7.

17. Jacqmin-Gadda H, Fabrigoule C, Commenges D, Dartigues JF. A 5-year longitudinal study of the Mini-Mental State Examination in normal aging. Am J Epidemiol 1997; 145:498-506.

18. Lyketsos CG, Chen LS, Anthony JC. Cognitive decline in adulthood: an 11.5-year follow-up of the Baltimore Epidemiologic Catchment Area study. Am J Psychiatry 1999; 156:58-65.

19. Colsher PL, Wallace RB. Longitudinal application of cognitive function measures in a defined population of community-dwelling elders. Ann Epidemiol 1991; 1:215-30.

20. Farmer ME, Kittner SJ, Rae DS, Bartko JJ, Regier DA. Education and change in cognitive function: the Epidemiologic Catchment Area study. Ann Epidemiol 1995; 5:1-7.

21. Butler SM, Ashford JW, Snowdow DA. Age, education, and changes in the Mini-Mental State Exam scores of older women: findings from the Nun Study. J Am Geriatr Soc 1996; 44:675-81.

22. Christensen H, Korten AE, Jorm AF, Henderson AS, Jacomb PA, Rodgers B, et al. Education and decline in cognitive performance: compensatory but not protective. Int J Geriatr Psychiatry 1997; 12:323-30.

23. Tombaugh TN, McIntyre NJ. The Mini-mental State Examination: a comprehensive review. J Am Geriatr Soc 1992; 40:922-35.

Submitted on 13/Dec/2010

Final version resubmitted on $12 /$ Jun/2011 Approved on 21/Jun/2011 